\title{
Parental modelling and prompting effects on acceptance of a novel fruit in 2-4-year-old children are dependent on children's food responsiveness
}

\author{
Jackie Blissett*, Carmel Bennett, Anna Fogel, Gillian Harris and Suzanne Higgs \\ School of Psychology, University of Birmingham, Edgbaston, Birmingham B15 2TT, UK \\ (Submitted 1 June 2015 - Final revision received 28 September 2015 - Accepted 26 October 2015 - First published online 25 November 2015)
}

\begin{abstract}
Few children consume the recommended portions of fruit or vegetables. This study examined the effects of parental physical prompting and parental modelling in children's acceptance of a novel fruit (NF) and examined the role of children's food-approach and food-avoidance traits on NF engagement and consumption. A total of 120 caregiver-child dyads (fifty-four girls, sixty-six boys) participated in this study. Dyads were allocated to one of the following three conditions: physical prompting but no modelling, physical prompting and modelling or a modelling only control condition. Dyads ate a standardised meal containing a portion of a fruit new to the child. Parents completed measures of children's food approach and avoidance. Willingness to try the NF was observed, and the amount of the NF consumed was measured. Physical prompting but no modelling resulted in greater physical refusal of the NF. There were main effects of enjoyment of food and food fussiness on acceptance. Food responsiveness interacted with condition such that children who were more food responsive had greater NF acceptance in the prompting and modelling conditions in comparison with the modelling only condition. In contrast, children with low food responsiveness had greater acceptance in the modelling control condition than in the prompting but no modelling condition. Physical prompting in the absence of modelling is likely to be detrimental to NF acceptance. Parental use of physical prompting strategies, in combination with modelling of NF intake, may facilitate acceptance of NF, but only in food-responsive children. Modelling consumption best promotes acceptance in children with low food responsiveness.
\end{abstract}

Key words: Children: Feeding practices: Parental modelling: Physical prompting: Fruits and vegetables

A balanced and varied diet is crucial to a child's optimal health and development ${ }^{(1)}$. The rise in the number of overweight and obese children and the associated rise in non-communicable diseases such as diabetes mellitus, CVD and some cancers over the past decades highlight the fact that the diet consumed by many children is not favourable to their weight or health status $^{(2)}$. The introduction of healthy foods into a child's diet at an early age is crucial $^{(3,4)}$. Food preferences developed during childhood are stable and enduring, influencing food choices in adulthood $^{(5)}$. Nevertheless, many parents find it difficult to successfully introduce healthy foods, especially fruits and vegetables, into their children's diets during infancy, and only $21.5 \%$ of $5-15$-year-olds in England consume the recommended five or more portions of fruits and vegetables a day ${ }^{(6)}$.

A variety of factors play an important role in whether or not children will consume fruits and vegetables ${ }^{(7,8)}$. These include parental feeding practices during infancy and childhood ${ }^{(9,10)}$, parental preferences, the accessibility and availability of fruits and vegetables, the child's social eating environment as well as genetically determined taste perception and appetite ${ }^{(7,8)}$. Of these, parental fruit and vegetable consumption is one of the strongest predictors of fruit and vegetable consumption in children ${ }^{(8,11)}$. Observing familiar others, especially parents, consume different foods and model their intake leads to the social facilitation of eating behaviour ${ }^{(12-14)}$. Furthermore, in households in which fruits and vegetables are consumed by parents, they are more readily available and accessible, leading to a child's greater exposure to fruits and vegetables ${ }^{(12,15,16)}$. A further predictor of children's eating behaviour is not what but how parents feed their children ${ }^{(17)}$. Pressure, typically measured by the degree of verbal instruction to consume or try foods, is one of the most investigated controlling feeding strategies used by parents. It is often used to encourage children, especially pre-school children, to eat new foods, more food in general or to eat foods deemed to be healthy ${ }^{(18,19)}$. However, despite parents' intentions to increase the intake of healthy foods, pressure to eat is negatively associated with children's fruit and vegetable consumption ${ }^{(8,11,20,21)}$.

Nevertheless, it is likely that a certain degree of less intrusive prompting or negotiating is necessary to encourage children to taste novel foods, leading to the exposure that will facilitate novel food acceptance ${ }^{(22)}$. In line with this suggestion,

Abbreviations: MC, modelling 'control' group; NF, novel fruit; PM, prompting and modelling; PNM, prompting no modelling.

* Corresponding author: Dr J. Blissett, fax + 44121414 4897, email j.blissett@bham.ac.uk 
Blissett et $a l .^{(18)}$ found that the number of parental physical prompts used during a mealtime, which included a novel fruit (NF), was significantly correlated with the number of taste experiences children had with the NF (measured by counting the number of times the child licked the NF, bit into it or put some of the NF into the mouth). The physical prompts parents used included passing the food into the child's hand, holding the food up to the child's face or replacing the rejected food back on to the child's plate, and these were independent of any verbal prompts. These results suggest that parental physical prompting may have a positive effect on dietary intake, promoting fruit and vegetable consumption under some circumstances. However, due to the cross-sectional nature of this study, it is unclear whether physical prompting facilitated acceptance or whether parents of children who were more willing to taste such foods used the practice more readily.

It is also the case that there are individual differences in children's appetite, enjoyment of food and willingness to try new foods ${ }^{(3,23-26)}$. Children tend to show relatively stable and continuous eating behaviour traits from early through to later childhood $^{(27)}$. These traits include those that are associated with food approach and a tendency to overeat, such as food responsiveness (the tendency to want to eat when food cues are present) and enjoyment of food (gaining great pleasure from eating behaviour), and those that are associated with greater satiety and food avoidance, such as satiety responsiveness (stopping eating when internal cues of fullness are noticed) and food fussiness (selectivity about food type and range $)^{(27)}$. These food-approach and food-avoidance traits have also been shown to be systematically correlated with child weight ${ }^{(28)}$ and actual eating behaviour ${ }^{(29)}$. In the context of this study, it is likely that children who show stronger 'food-approach' tendencies will accept new foods more readily and may both elicit and respond differently to different parental feeding practices than children with high levels of food avoidance.

As previous research has indicated that the use of parental physical prompts during a mealtime is positively correlated with a child's willingness to try a $\mathrm{NF}^{(18)}$, this study aimed to establish whether caregivers who had been instructed on how to use physical prompting would be more successful in introducing the NF than caregivers who had not been instructed in prompting. We also examined whether a combination of modelling and prompting would be more successful than prompting or modelling alone. Finally, we aimed to examine whether children's food-approach or food-avoidance tendencies interacted with modelling and prompting conditions in order to determine their effects on child NF acceptance.

We assessed engagement with the NF, measured by behaviours indicating willingness to approach/interact with the $\mathrm{NF}$ as well as the actual consumption of the NF to allow us a more sensitive measure of acceptance than consumption and rejection alone. On the basis of previous research, we hypothesised that children of caregivers who received instructions on how to prompt would be more likely to engage with, and consume more of, a NF than children of caregivers who received no instructions on prompting. In addition, we hypothesised that children of caregivers who received instructions on how to prompt would be more likely to engage with, and consume more of, a NF if their caregivers also consumed the NF compared with if their caregivers had been instructed not to eat the NF themselves. In accordance with the literature, we hypothesised that those children with higher food-approach behaviours (food responsiveness, enjoyment of food) and those children with lower food-avoidant behaviours (food fussiness, satiety responsiveness) would show greater acceptance of the NF and that the effectiveness of parental prompting would be greater in those children with higher levels of food-approach behaviours and children with lower food-avoidance behaviours.

\section{Methods}

\section{Participants}

A total of 120 caregiver-child dyads were recruited to this experimental study. Caregivers and their children were recruited through the Infant and Child Laboratory database, which contains information on families in which caregivers have indicated an interest in research participation at the University of Birmingham. The caregivers who participated in this study were the primary caregivers of their children; where fathers $(n 2)$ or grandmothers ( $n$ 4) participated, they were primary or equal caregivers. Before the caregiver-child dyads visited the university, pre-screening questions were asked to ascertain whether children had eaten all of the lunch foods and any of the three NF (dried date, tinned lychee or fresh fig) before. Inclusion criteria for children included the absence of known food allergies or disorders affecting eating, current or recent major illness or diagnosed intellectual disabilities. Caregiver-child dyads were assigned at random to one of three conditions and received different instructions on the mealtime behaviours they were asked to exhibit during the mealtime. Block randomisation was used to allocate to groups in blocks of ten participants with conditions changing each week, allocated in order of recruitment. However, due to failure to attend sessions and/or data loss, group sizes were unequal at the end of data collection (see below). Caregivers in all three conditions received identical information on changes in children's willingness to try new foods between the age of 2 and 6 years. Specific instructions given to the caregivers for each of the three conditions can be seen below. Caregivers were classified as prompting if they used any of the prompting behaviours described, for a minimum of three times during the mealtime. Although most caregivers were compliant with the instructions given about mealtime behaviours they were asked to exhibit or omit, a few caregivers failed to follow them, resulting in some caregivers eating the NF when they were asked not to eat it or not eating the NF when they were asked to eat it or failing to use the instructed prompting behaviours for a minimum of three times. To address these issues, caregivers-child dyads that were not compliant with the instructions were removed from the analysis ( $n$ sizes given below). In addition to the instructions given, all caregivers were asked to keep the mealtime as natural as possible, and to respond as they would normally do to any aspects of the mealtime.

Condition 1: Parental use of physical prompts to eat the novel food without eating the novel food (prompting no modelling). Caregivers were asked to use physical prompts to eat the NF (including passing the food to the child, moving the 
food towards the child, holding the NF up to the child's face, encouraging the child to touch the NF). To avoid this prompting behaviour developing into pressure to eat, the parent was instructed to only encourage trying of the food (not to force consumption). The caregivers assigned to this condition were asked not to taste the $\mathrm{NF}$ themselves. Of an original sample of fifty, fifteen were classed as non-compliant: ten caregivers failed to prompt a minimum of three times, and five caregivers were removed from the group because they ate the NF. This left a sample of thirty-five parents who physically prompted but did not model eating the fruit.

\section{Condition 2: Parental use of physical prompts to eat the} novel food and eating the novel food (prompting and modelling). Caregivers were asked to use physical prompts to eat the NF as described above. The caregivers assigned to this condition were also asked to try the NF themselves. Caregivers were not instructed on how to react to the NF. Of an original sample of forty-three dyads, six were non-compliant because the parent failed to prompt three times or more, leaving a sample of thirty-seven parents who prompted and modelled eating the fruit.

\section{Condition 3: Parental eating of the novel fruit but no} training in physical prompts (modelling 'control' group). Caregivers in this condition were not given any information about prompting, but were simply asked to taste the NF themselves. There were twenty-seven dyads in this condition, in which the parent modelled eating of the fruit; all were compliant with this request.

\section{Questionnaire measures}

Demographic information. Caregivers provided information on their age, number of persons in their household, ethnicity, household income and level of education. Caregivers also reported their child's age, sex, breast-feeding duration, age at introduction of complementary foods and their daytime care arrangements because these factors are frequently associated with children's eating behaviour and parental feeding practices.

Child eating behaviour. The Children's Eating Behaviour Questionnaire $^{(30)}$ was used to measure children's foodapproach and food-avoidance behaviours. The thirty-five-item scale consists of eight subscales, four of which assess foodapproach behaviours (food responsiveness, enjoyment of food, desire to drink and emotional overeating) and four that assess food-avoidance behaviours (satiety responsiveness, slowness in eating, emotional under-eating and food fussiness). In this study, we focused on two food-approach and two foodavoidance subscales - food responsiveness, enjoyment of food, satiety responsiveness and food fussiness - because these subscales have been associated with behavioural measures of child eating behaviour ${ }^{(29,31)}$. The Cronbach's $\alpha$ s for each subscale were as follows: food responsiveness: $0 \cdot 70$, enjoyment of food: $0 \cdot 40$, satiety responsiveness: 0.73 and food fussiness: 0.87 , indicating good reliability for all subscales with the exception of enjoyment of food.
Child neophobia. To ensure our groups of children did not differ in neophobia, we administered the Child Food Neophobia Scale ${ }^{(32)}$. This measure assesses parental perceptions of children's willingness to try new foods. Analysis of Cronbach's $\alpha$ s indicated best internal consistency ( $\alpha=0.88)$ from inclusion of only three items: 'My child doesn't trust new foods', 'If my child doesn't know what is in a food, she/he won't try it' and 'My child is afraid to eat things she/he has never eaten before'. A sum of these three items was calculated as an index of child neophobia.

\section{Apparatus}

Recording equipment. The mealtimes were recorded using two remotely adjustable cameras, which were located in two opposite corners of the observation room. Recordings were processed using a picture-in-picture processor that ensured that the caregiver's and the child's faces could be seen on the screen at the same time.

Food preparation. The caregivers' and children's foods were presented on identical white, round porcelain plates $(\varnothing=18 \mathrm{~cm})$. Water was presented in identical glasses.

Mealtime foods. Caregivers and children each received a standardised meal with a novel fruit presented on the same plate. All meal items were weighed on scientific scales before and after consumption. Depending on the caregivers' preindicated preference, the children's lunch consisted of half a ham or cheese sandwich made with white bread with added wheatgerm (Hovis Best of Both) (approximately $502 \mathrm{~kJ}$ (120 kcal) or $523 \mathrm{~kJ}$ ( $125 \mathrm{kcal}$ ), respectively, J. Sainsbury Plc.), $10 \mathrm{~g}$ ready salted potato crisps (approximately $222 \mathrm{~kJ}$ (53 kcal), Walkers Snack Food Ltd), two chocolate-chip cookies (approximately 477 kJ (114 kcal), Burton's Foods Ltd), five milkchocolate buttons (approximately $146 \mathrm{~kJ}$ (35 kcal), Cadbury Plc.) and five green grapes (approximately $75 \mathrm{~kJ}$ (18 kcal)). Caregivers received a lunch identical to that of their children's, except that they were given a whole ham or cheese sandwich, depending on their pre-indicated preference (approximately $1004 \mathrm{~kJ}$ ( $240 \mathrm{kcal})$ or $1046 \mathrm{~kJ}$ (250 kcal), respectively, J. Sainsbury Plc.). Meal foods were chosen to reflect typical lunchtime meals eaten by children in the UK. As the novel fruit presented as part of the meal needed to be novel to all children, it was not possible to use the same fruit in all conditions. A whole dried date without the stone (approximately $96 \mathrm{~kJ}$ ( $23 \mathrm{kcal})$ ), a tinned lychee without the stone (approximately $88 \mathrm{~kJ}$ ( $21 \mathrm{kcal})$ ) or a quarter of a fresh fig (approximately $50 \mathrm{~kJ}$ (12 kcal)) were presented as NF. These fruits were selected as they have unusual characteristics and at least one was novel to all children within the sample. In cases where children had not consumed any of the NF before, NF were presented evenly across participants and sessions through randomisation. However, because of previous consumption of the NF by several children, dried date was used in twenty-four mealtimes, tinned lychee in forty-four mealtimes and fresh fig in thirty-three mealtimes. However, importantly, there were no effects of type of fruit on outcome or any interaction between fruit and condition (see the 'Results' 
section). Owing to differences in weights of the different NF offered, it was not possible to compare conditions based on simple weight of consumption. Therefore, we calculated consumption of the NF based on the percentage consumed of the whole portion offered.

\section{Procedure}

This study was conducted according to the guidelines laid down in the Declaration of Helsinki, and all procedures were approved by the Ethical Review Committee of the University of Birmingham (ERN 10-0010). All caregivers gave their written informed consent before participation. Caregivers and children attended the Infant and Child Laboratory's observation room for one session, during which - after a period of familiarisation they sat in specific seats at the table in order to ensure optimal capture of parent and child behaviours displayed during the mealtime. Each parent-child dyad was tested separately. Lunch was presented and the researcher left the room and followed the session on a monitor in the adjacent room, from which discreet wall-mounted cameras were controlled by the researcher. After caregivers and children had finished their lunch, taking as long as they needed, caregivers completed the questionnaire. Children and caregivers were then measured and weighed by a trained researcher at the laboratory in order to determine their height and weight and subsequently BMI for caregivers and BMI $z$-scores (BMI adjusted for age and sex) for children.

\section{Analysis}

Video analysis. An adaptation of the Family Mealtime Coding Scale ${ }^{(33)}$ was used to code the parental feeding strategies observed during the mealtimes. Parental feeding strategies were grouped into twelve categories. Nine of these categories addressed feeding strategies that were specific to the NF, including physical prompting of the NF to the child's plate, hand or face/body, verbal prompting of the NF, modelling of $\mathrm{NF}$ consumption, role play including the $\mathrm{NF}$, comparison of the $\mathrm{NF}$, teaching about the NF and rewarding/bargaining NF consumption. Three categories additionally addressed parental feeding strategies specific to the other constituents of the meal, including physical prompting of mealtime foods, verbal prompting of mealtime intake and general comments about the mealtime. Detailed descriptions and corresponding examples for each category of strategies within the video coding schedule can be seen in Table 1.

Children's 'engagement' behaviours towards the NF and the mealtime foods were grouped into eight categories: physical refusal, verbal refusal, smelling the NF, licking the NF, placing the NF in the mouth, swallowing the NF, physical refusal of the mealtime foods and verbal refusal of the mealtime foods.

Table 1. Descriptions of parental feeding strategies and examples

\begin{tabular}{|c|c|c|}
\hline Behaviour categories & Descriptions of the behaviour & Examples \\
\hline Physical prompt to plate (NF) & $\begin{array}{l}\text { The parent passes NF from the table or own plate onto } \\
\text { child's plate }\end{array}$ & $\begin{array}{l}\text { After the child takes the NF off his/her plate and puts it on the } \\
\text { table, the mother places it back on his/her plate }\end{array}$ \\
\hline Physical prompt to hand (NF) & The parent places the NF into the child's hand & $\begin{array}{l}\text { The mother takes the child's hand and puts the NF into the } \\
\text { palm of his/her hand }\end{array}$ \\
\hline Physical prompt to face (NF) & The parent brings the NF closer to the child's face & $\begin{array}{l}\text { The mother picks up the NF and holds it up in front of the } \\
\text { child's face/mouth }\end{array}$ \\
\hline Verbal prompt (NF) & $\begin{array}{l}\text { Parental comments that aim to increase verbal } \\
\text { prompting of NF consumption. Any comment to } \\
\text { encourage the child to consume the NF }\end{array}$ & 'Try it', 'Eat it', 'Try a little bit' \\
\hline Modelling (NF) & $\begin{array}{l}\text { Parent models the actual or pretended ingestion of the } \\
\text { NF/eats it. Parent comments on ingesting the NF. } \\
\text { Parent makes noises during NF ingestion or } \\
\text { pretended ingestion. Distant modelling - parent uses } \\
\text { a non-present other to model the NF consumption }\end{array}$ & $\begin{array}{l}\text { 'Look, Mummy is eating it', 'Mmmmh', 'Yummy', 'Daddy/ } \\
\text { Grandma really likes these' }\end{array}$ \\
\hline Role play (NF) & $\begin{array}{l}\text { Pretending a puppet/toy is eating the NF. Pretending } \\
\text { that the NF is alive and can speak }\end{array}$ & $\begin{array}{l}\text { 'I think Thomas the tank engine would love to try some date', } \\
\text { mother pretends to feed Thomas the tank engine, 'Hello, my } \\
\text { name is Mr. Lychee, would you like to try me?' }\end{array}$ \\
\hline Comparison (NF) & $\begin{array}{l}\text { Parent compares the NF with something that looks or } \\
\text { tastes similar }\end{array}$ & $\begin{array}{l}\text { 'Dates are like big raisins, don't they', 'Look, the lychee looks } \\
\text { like an egg' }\end{array}$ \\
\hline Teaching (NF) & $\begin{array}{l}\text { Parent teaches the child about the NF sensory } \\
\text { properties (taste, texture, colour, smell) or other } \\
\text { aspects such as history and eating context }\end{array}$ & $\begin{array}{l}\text { 'Dates are really sticky', 'Figs smell like cucumber', 'Lychees } \\
\text { are really sweet', 'People eat dates around Christmas time', } \\
\text { 'Figs are good for your bowels', 'Inside, there's a big stone', } \\
\text { 'It's a fruit' }\end{array}$ \\
\hline Rewarding/bargaining (NF) & $\begin{array}{l}\text { Parent rewards the child for eating the NF with another } \\
\text { food or different non-edible incentives }\end{array}$ & $\begin{array}{l}\text { 'If you try some of your fig you can have another cookie/you } \\
\text { can go and play' }\end{array}$ \\
\hline Physical prompting (mealtime) & $\begin{array}{l}\text { Physical prompting of any of the mealtime foods, but } \\
\text { not of the NF }\end{array}$ & $\begin{array}{l}\text { Placing the food on the child's plate, placing it in the child's } \\
\text { hand, bringing it closer to the child's face/body }\end{array}$ \\
\hline Verbal prompting (mealtime) & $\begin{array}{l}\text { Verbal prompting of lunch food consumption but not of } \\
\text { NF consumption. Any comment to encourage the } \\
\text { child to consume the meal foods }\end{array}$ & 'Eat your grapes', 'Have some more sandwich' \\
\hline General comments (mealtime) & $\begin{array}{l}\text { General comments about the mealtime, but not specific } \\
\text { attempts to encourage food consumption }\end{array}$ & $\begin{array}{l}\text { 'What have you got on your plate', 'Mummy has sandwiches } \\
\text { too', 'Are the grapes your favourite?' }\end{array}$ \\
\hline
\end{tabular}

NF, novel fruit. 
Table 2. Descriptions of children's behaviours towards the novel fruit (NF) and mealtime foods and examples

\begin{tabular}{|c|c|c|}
\hline Child behaviour & Description & Examples \\
\hline (1) Physical refusal & $\begin{array}{l}\text { Any occurrence of the child physically refusing the NF in } \\
\text { response to the parent offering the NF or due to the } \\
\text { general presence of the NF on the child's plate }\end{array}$ & $\begin{array}{l}\text { Leaving the table, covering the mouth, turning the head away, } \\
\text { blocking the parent's hand or pushing it away if the parent } \\
\text { tries to offer the NF, removing the NF from the plate, } \\
\text { throwing the NF onto the table/floor }\end{array}$ \\
\hline (2) Verbal refusal & Any occurrence of the child verbally refusing the NF & 'I don't like this', 'I don't want to eat this', screaming, crying \\
\hline (3) Smelled & $\begin{array}{l}\text { Any occurrence of the child smelling the NF, either by } \\
\text { picking it up and bringing it to the nose or through } \\
\text { parental offering, but no further interaction with it }\end{array}$ & $\begin{array}{l}\text { Smelling the NF after picking it up or in response to the parent } \\
\text { bringing it closer to the child's face }\end{array}$ \\
\hline (4) Licked & $\begin{array}{l}\text { Any occurrence of the child licking the NF, either by picking } \\
\text { it up and bringing it to the mouth or through parental } \\
\text { offering, but no further interaction with it }\end{array}$ & $\begin{array}{l}\text { Licking the NF after picking it up or in response to the parent } \\
\text { bringing it closer to the child's face }\end{array}$ \\
\hline (5) Placed in mouth & $\begin{array}{l}\text { Any occurrence of the child placing the NF inside the } \\
\text { mouth, but no further interaction or its consumption }\end{array}$ & $\begin{array}{l}\text { Putting the NF into the mouth without biting it, holding it inside } \\
\text { the mouth and then taking/spitting in back out }\end{array}$ \\
\hline (6) Swallowed & $\begin{array}{l}\text { Any occurrence of the child chewing and swallowing a } \\
\text { piece of the NF }\end{array}$ & Biting off a piece of the NF, chewing and swallowing it \\
\hline
\end{tabular}

Detailed descriptions and corresponding examples for each category of child behaviours can be seen in Table 2 .

Children's engagement behaviours were not mutually exclusive; a range of behaviours towards the NF was displayed and recorded during mealtimes, and a child that licked the NF initially could have swallowed and enjoyed it subsequently, or vice versa. In addition to recording the frequency of the different engagement behaviours, we also recorded the child's greatest observed engagement with the NF, with higher engagement scores indicating greater willingness to try the NF. These scores ranged from physical refusal (1) to swallowing the NF (6) - for example, if a child only displayed physical refusal (1) and verbal refusal (2), but no further interaction with the NF, then verbal refusal (2) was noted as the greatest observed engagement. If a child, however, smelled the NF (3) but later swallowed it (6), swallowed (6) was noted as the most successful outcome of the mealtime. The behavioural coding software ObsWin ${ }^{(34)}$ was used to code the occurrence of our predetermined parental feeding strategies and child behaviours. Raters could not be fully blinded to the condition due to the occurrence of explicit behaviours coded for each category. However, two researchers second-coded the data without knowledge of the study subgroups, from which inter-rater reliability was calculated for $26 \%$ of the mealtimes. Two-way mixed effects model intra-class correlation coefficients were calculated, yielding a mean intra-class coefficient of 0.56 , indicating adequate inter-rater reliability.

\section{Statistical analysis}

The criterion $\alpha$ for significance was $0 \cdot 05$. Stem-and-leaf plots were inspected and indicated that the majority of data were normally distributed; parametric tests were therefore conducted on all variables. Initially, sample characteristics were inspected and possible differences between groups and sex differences were identified using one-way ANOVA with post-hoc Bonferroni corrections. A per-protocol analysis was undertaken; results of participants who did not adhere to the protocol were eliminated from the analyses. After this, as a manipulation check, the frequency of the strategies and differences in the use of the strategies were assessed, and differences based on the condition caregiver-child dyads were examined using multivariate ANCOVA (MANCOVA), controlling for child age effects, or $\chi^{2}$ where necessary. Subsequently, differences in a child's engagement with and consumption of a NF based on the condition the parent-child dyad was in and the child's eating characteristics (based on median splits of food responsiveness, enjoyment of food, food fussiness and satiety responsiveness) were examined. A series of 3 (condition) $\times 2$ (high $v$. low eating behaviour tendencies) ANCOVA controlling for child age was calculated to examine main and interaction effects on children's engagement with and consumption of the NF. Interaction effects were examined using simple main effects analyses controlling for child age.

\section{Results}

\section{Sample characteristics}

The sample characteristics and differences between the three conditions were analysed and are summarised in Table 3.

There were no significant group differences in mothers' age and BMI, children's BMI $z$-score, weaning age, length of being exclusively breast-fed or number of hours per week spent in day care. There was a significant difference in children's age, where children in the prompting no modelling (PNM) condition were significantly younger than children in the MC condition, and thus child's age was controlled for in the subsequent analyses. None of the other factors were considered in the subsequent analyses, given the lack of group differences. Overall, forty-seven girls and fifty-two boys participated in the study, and the distribution of children's sex was balanced across the three conditions $\left(\chi^{2}(2, n 99)=2.501 ; P=0.286\right)$, and there were no sex differences in acceptance. There was no effect of fruit type used on intake $\left(F_{2,98}=0.55 ; P=0.57\right)$ or the child's willingness to try the fruit $\left(F_{2,95}=2 \cdot 10 ; P=0 \cdot 13\right)$, or any interaction between fruit and condition on intake $\left(F_{4,98}=1.45\right.$; $P=0 \cdot 23)$ or willingness to try the fruit $\left(F_{4,95}=1 \cdot 81 ; P=0 \cdot 13\right)$. There was a small difference in parental reports of fussiness between the conditions; children in the PNM condition were 
Table 3. Sample characteristics for participants in each condition and differences in characteristics based on condition (Mean values and standard deviations per group and associated $F$ values of ANOVA)

\begin{tabular}{|c|c|c|c|c|c|c|c|}
\hline & \multicolumn{2}{|c|}{ PNM ( $n$ 35) } & \multicolumn{2}{|c|}{$\mathrm{PM}(n 37)$} & \multicolumn{2}{|c|}{$\mathrm{MC}(n 27)$} & \multirow[b]{2}{*}{$F$} \\
\hline & Mean & SD & Mean & SD & Mean & SD & \\
\hline Mother's age (years) & 33.97 & 6.04 & 35.97 & $4 \cdot 18$ & $35 \cdot 00$ & 4.52 & $1 \cdot 35$ \\
\hline Mother's BMI $\left(\mathrm{kg} / \mathrm{m}^{2}\right)$ & $25 \cdot 70$ & 4.69 & 25.94 & $5 \cdot 60$ & $24 \cdot 70$ & $5 \cdot 26$ & 0.45 \\
\hline Child's age (months) & $27 \cdot 45$ & $4 \cdot 26$ & $29 \cdot 22$ & 4.93 & $31 \cdot 30$ & 4.01 & $5 \cdot 52^{\star \star}(\mathrm{PNM}<\mathrm{MC})$ \\
\hline Child's weight (z-score) & 0.82 & $2 \cdot 29$ & 0.69 & $2 \cdot 29$ & 0.33 & 1.84 & 0.40 \\
\hline Weaning age (months) & 5.93 & 2.99 & 5.45 & $1 \cdot 27$ & $5 \cdot 71$ & $1 \cdot 16$ & 0.42 \\
\hline Exclusively breast-fed (months) & 4.66 & $1 \cdot 81$ & $5 \cdot 64$ & 3.68 & 4.59 & $2 \cdot 35$ & $1 \cdot 22$ \\
\hline Day care category $\dagger$ & 2.09 & 1.03 & 2.42 & $1 \cdot 12$ & 2.58 & 1.07 & 1.57 \\
\hline CEBQ food responsiveness & $2 \cdot 39$ & 0.98 & 2.05 & 0.91 & $2 \cdot 44$ & 0.57 & 0.89 \\
\hline CEBQ enjoyment of food & $3 \cdot 71$ & 1.29 & 3.43 & $1 \cdot 29$ & $3 \cdot 78$ & 0.64 & 1.99 \\
\hline CEBQ satiety responsiveness & $2 \cdot 82$ & 1.00 & $2 \cdot 81$ & 1.03 & 2.96 & 0.50 & 0.22 \\
\hline CEBQ food fussiness & $2 \cdot 36$ & 1.05 & $2 \cdot 71$ & 1.09 & 3.00 & 0.79 & $3 \cdot 15^{\star}(\mathrm{PNM}<\mathrm{MC})$ \\
\hline Neophobia & $9 \cdot 78$ & 2.59 & 9.89 & $2 \cdot 71$ & 9.63 & $2 \cdot 62$ & 0.07 \\
\hline
\end{tabular}

PNM, prompting no modelling; PM, prompting and modelling; MC, modelling 'control' group; CEBQ, Children's Eating Behaviour Questionnaire.

${ }^{*} P<0.05,{ }^{* *} P<0.01$.

† $1=0 \mathrm{~h} /$ week; $2=1-10 \mathrm{~h} /$ week; $3=11-25 \mathrm{~h} /$ week; $4=26-40 \mathrm{~h} /$ week; $5=40+\mathrm{h} /$ week.

rated as slightly less fussy than children in the MC condition. Controlling for fussiness (in analyses where fussiness was not the basis of the median split) made no difference to the pattern of results. Child neophobia did not significantly differ between the conditions $\left(F_{2,93}=0.07 ; P=0.93\right)$.

\section{Manipulation check: feeding strategies by condition}

To check that the manipulation had the desired effect on feeding practice, a MANCOVA controlling for child age confirmed that there was a significant effect of condition on feeding practices (Pillai's trace $F_{24,164}=3.93 ; P<0.0001$ ). Tests of between-subjects effects showed that there were significant differences between the conditions in the frequency of modelling, physical prompts to the plate, physical prompts to the child's hand and total number of physical prompts, consistent with condition manipulation. Table 4 shows the profile of feeding strategies used by caregivers in the different conditions. No differences in the frequency with which any other feeding practices were used were observed.

\section{Children's behaviour with the novel fruit by condition}

To examine whether children of caregivers who received instructions on how to prompt would be more likely to engage with, and consume more of, a NF than children of caregivers who received no instructions on prompting, and whether children of caregivers who received instructions on how to prompt would be more likely to engage with, and consume more of, a NF if their caregivers also consumed the NF, a MANCOVA controlling for child age was conducted. This suggested that there was no significant effect of condition on children's mealtime and eating behaviour (Pillai's trace $F_{16,164}=0.814 ; P=0 \cdot 67$ ). However, tests of between-subjects effects showed that there was a significant difference between the conditions in the frequency of physical refusal of the NF, with children in the PNM condition physically refusing the NF more frequently than children in the modelling 'control' (MC) condition. Table 5 shows the profile of children's mealtime and eating behaviours in the different conditions. Neither was there a significant effect of condition on whether children had any taste of the NF or not $\left(\chi^{2}=4 \cdot 24, \mathrm{df}=2 ; P=0 \cdot 12\right)$, although only just over half of the children in the PNM group tasted the NF, in contrast to over $70 \%$ of the children in the prompting and modelling (PM) and MC groups.

\section{Food approach and avoidance and novel fruit acceptance}

To examine whether those children with higher food-approach behaviours and those children with lower food-avoidant behaviours would show greater acceptance of the NF and whether the effectiveness of parental prompting would be greater in those children with higher levels of food-approach behaviours and children with lower food-avoidance behaviours, a series of ANCOVA controlling for child age were conducted. These were calculated first for percentage of the NF consumed and second for the greatest observed engagement with the NF.

Percentage of novel fruit consumed. ANCOVA controlling for child age were carried out to assess differences in children's consumption of the NF, measured by the percentage of the offered NF consumed by the child during the mealtime, based on condition and median splits of food-approach/avoidance traits. There were no significant main effects of satiety responsiveness $(P=0 \cdot 36)$, food responsiveness $(P=0 \cdot 87)$ or enjoyment of food $(P=0.46)$ on the percentage of the NF consumed by the child. There was a main effect of fussiness on the percentage of NF consumed $\left(F_{1,84}=7.39 ; P=0.008\right)$. Pairwise comparisons showed that more fussy children consumed less of the NF $(P<0.008$; low food fussiness mean percentage consumed 39.5 (SD 40.3); high food fussiness mean percentage consumed 18.4 (SD 32.8)). There was no interaction with condition $(P=0.55)$.

Greatest observed engagement. ANCOVA controlling for child age were carried out to assess differences in children's 
Table 4. Feeding strategies used by caregivers during mealtimes† (Minimum and maximum values; mean values and standard deviations)

\begin{tabular}{|c|c|c|c|c|}
\hline \multirow[b]{2}{*}{ Variables } & \multicolumn{3}{|c|}{ Conditions } & \multirow[b]{2}{*}{$F$ value and results of pairwise post-hoc tests } \\
\hline & PNM $(n$ 35) & $\mathrm{PM}(n 37)$ & $\mathrm{MC}(n 27)$ & \\
\hline \multicolumn{5}{|c|}{ Novel fruit } \\
\hline \multicolumn{5}{|l|}{ Physical prompting } \\
\hline Face & & & & $2 \cdot 12$ \\
\hline Minimum-maximum & $0-26$ & $0-12$ & $0-7$ & \\
\hline Mean & 4.23 & 3.70 & 1.85 & \\
\hline SD & 5.36 & 3.45 & $2 \cdot 16$ & \\
\hline Hand & & & & $5 \cdot 77^{\star}(\mathrm{MC}<\mathrm{PM}=\mathrm{PNM})$ \\
\hline Minimum-maximum & $0-11$ & $0-2$ & $0-1$ & \\
\hline Mean & 1.06 & 0.43 & 0.04 & \\
\hline SD & 2.06 & 0.69 & 0.19 & \\
\hline Plate & & & & $6 \cdot 66^{*}(\mathrm{MC}<\mathrm{PM}=\mathrm{PNM})$ \\
\hline Minimum-maximum & 0-19 & $0-13$ & $0-5$ & \\
\hline Mean & 3.91 & 3.65 & 1.30 & \\
\hline SD & 3.70 & $2 \cdot 71$ & 1.56 & \\
\hline Total physical prompts & & & & $8.46^{*}(\mathrm{MC}<\mathrm{PM}=\mathrm{PNM})$ \\
\hline Minimum-maximum & $1-44$ & $1-18$ & $0-10$ & \\
\hline Mean & $9 \cdot 20$ & 7.78 & $3 \cdot 19$ & \\
\hline SD & 8.30 & 4.64 & 2.66 & \\
\hline Verbal prompt & & & & 2.79 \\
\hline Minimum-maximum & $1-21$ & $0-29$ & $0-24$ & \\
\hline Mean & 5.06 & 6.95 & 7.96 & \\
\hline SD & 4.84 & $6 \cdot 01$ & $6 \cdot 22$ & \\
\hline Modelling & & & & $29.45^{\star \star}(\mathrm{PNM}<\mathrm{PM}=\mathrm{MC})$ \\
\hline Minimum-maximum & $0-7$ & $0-11$ & $0-11$ & \\
\hline Mean & 0.54 & 4.46 & $4 \cdot 11$ & \\
\hline SD & 1.56 & 2.63 & 3.11 & \\
\hline Role play & & & & 1.48 \\
\hline Minimum-maximum & $0-5$ & $0-5$ & $0-11$ & \\
\hline Mean & 0.49 & 0.59 & $1 \cdot 15$ & \\
\hline SD & $1 \cdot 20$ & 1.34 & 2.85 & \\
\hline Comparison & & & & 1.52 \\
\hline Minimum-maximum & $0-8$ & $0-5$ & $0-6$ & \\
\hline Mean & 0.97 & 0.62 & 1.52 & \\
\hline SD & 1.79 & 1.04 & 2.06 & \\
\hline Rewarding/bargaining & & & & 1.88 \\
\hline Minimum-maximum & $0-8$ & $0-7$ & $0-9$ & \\
\hline Mean & 0.63 & 0.54 & 1.41 & \\
\hline SD & 1.73 & 1.32 & $2 \cdot 41$ & \\
\hline Teaching & & & & 0.12 \\
\hline Minimum-maximum & $0-16$ & $0-10$ & $0-9$ & \\
\hline Mean & 2.43 & $2 \cdot 14$ & 2.59 & \\
\hline SD & 3.58 & $2 \cdot 32$ & 2.50 & \\
\hline \multicolumn{5}{|c|}{ Other mealtime foods } \\
\hline General comments & & & & 2.60 \\
\hline Minimum-maximum & $0-34$ & $0-32$ & $0-42$ & \\
\hline Mean & 6.60 & 7.76 & 12.03 & \\
\hline SD & 7.96 & $7 \cdot 24$ & 11.85 & \\
\hline Physical prompt & & & & 0.74 \\
\hline Minimum-maximum & $0-30$ & $0-36$ & $0-10$ & \\
\hline Mean & 4.03 & 4.22 & 1.96 & \\
\hline SD & 6.55 & 6.85 & 2.68 & \\
\hline Verbal prompt & & & & 1.21 \\
\hline Minimum-maximum & $0-24$ & $0-37$ & $1-31$ & \\
\hline Mean & $7 \cdot 40$ & 9.81 & 9.56 & \\
\hline SD & 6.25 & 9.33 & $6 \cdot 77$ & \\
\hline
\end{tabular}

PNM, prompting no modelling; PM, prompting and modelling; MC, modelling 'control' group. ${ }^{*} P<0.01,{ }^{* *} P<0.0001$.

† Differences in the use of different feeding strategies by condition as indicated by multivariate ANCOVA controlling for child age.

willingness to try the NF, measured by the 'best outcome' observed from the child during the mealtime, based on condition and median splits of food-approach/avoidance traits.
Food fussiness and greatest observed engagement. There was a main effect of fussiness $\left(F_{1,87}=8.75 ; P=0.004\right)$ and no significant interaction between condition and food fussiness on acceptance of the NF. Pairwise comparisons showed that 
Table 5. Observed children's mealtime and eating behaviours $†$

(Minimum and maximum values; mean values and standard deviations)

\begin{tabular}{|c|c|c|c|c|}
\hline \multirow[b]{2}{*}{ Variables } & \multicolumn{3}{|c|}{ Conditions } & \multirow[b]{2}{*}{$F$ value and results of pairwise post-hoc tests } \\
\hline & PNM $(n$ 35) & $\mathrm{PM}(n 37)$ & $\mathrm{MC}(n 27)$ & \\
\hline Frequency of physical refusal of the NF & & & & $3 \cdot 12^{*}(\mathrm{PNM}>\mathrm{MC})$ \\
\hline Minimum-maximum & $0-18$ & $0-11$ & $0-8$ & \\
\hline Mean & 4.54 & 3.91 & 2.48 & \\
\hline SD & 4.47 & 2.93 & $2 \cdot 28$ & \\
\hline Frequency of verbal refusal of the NF & & & & 0.05 \\
\hline Minimum-maximum & $0-16$ & $0-10$ & $0-12$ & \\
\hline Mean & 3.97 & 3.76 & 3.67 & \\
\hline SD & 3.65 & $2 \cdot 77$ & 3.05 & \\
\hline Frequency of smelling but refusing the NF & & & & 0.20 \\
\hline Minimum-maximum & $0-2$ & $0-3$ & $0-4$ & \\
\hline Mean & 0.29 & 0.24 & 0.26 & \\
\hline SD & 0.62 & 0.64 & 0.81 & \\
\hline Frequency of licking but refusing the NF & & & & 0.92 \\
\hline Minimum-maximum & $0-4$ & $0-3$ & $0-1$ & \\
\hline Mean & 0.31 & 0.54 & 0.30 & \\
\hline SD & 0.80 & 0.93 & 0.47 & \\
\hline Frequency of holding in mouth but refusing the NF & & & & 0.50 \\
\hline Minimum-maximum & $0-3$ & $0-4$ & $0-4$ & \\
\hline Mean & 0.32 & 0.43 & 0.48 & \\
\hline SD & 0.73 & 0.93 & 1.01 & \\
\hline Frequency of swallowing the NF & & & & 3.08 \\
\hline Minimum-maximum & $0-5$ & $0-8$ & $0-12$ & \\
\hline Mean & 0.74 & 1.84 & $2 \cdot 11$ & \\
\hline SD & 1.44 & $2 \cdot 17$ & $2 \cdot 83$ & \\
\hline Greatest observed engagement & & & & $2 \cdot 88$ \\
\hline Minimum-maximum & $1-6$ & $2-6$ & $1-6$ & \\
\hline Mean & 3.77 & 4.72 & 4.88 & \\
\hline $\mathrm{SD}$ & 1.78 & 1.73 & 1.64 & \\
\hline Percentage of NF consumed & & & & 0.82 \\
\hline Minimum-maximum & $0-100$ & $0-100$ & $0-100$ & \\
\hline Mean & 21.51 & 34.0 & 31.88 & \\
\hline SD & 32.74 & $41 \cdot 15$ & 39.90 & \\
\hline Total taste exposures & & & & 2.95 \\
\hline Minimum-maximum & $0-7$ & $0-8$ & $0-16$ & \\
\hline Mean & 1.35 & $2 \cdot 81$ & $2 \cdot 88$ & \\
\hline SD & 1.88 & 2.45 & 3.70 & \\
\hline Number of children who had at least one taste of the NF & $18 \quad 51.4 \%$ & $2670.3 \%$ & $2074.1 \%$ & $x^{2}=4 \cdot 24$ \\
\hline
\end{tabular}

PNM, prompting no modelling; PM, prompting and modelling; MC, modelling 'control' group; NF, novel fruit.

${ }^{*} P<0.05$.

† Differences by condition as indicated by multivariate ANCOVA controlling for child age and frequency of at least one taste exposure to the NF by condition.

fussy children showed least engagement with the NF $(P=0.004$; low food fussiness mean engagement 5.0 (SD 1.6); high food fussiness mean engagement 3.9 (SD 1.8))

\section{Satiety responsiveness and greatest observed engagement.}

There was no significant main effect of satiety responsiveness on engagement with the NF. There was no interaction between condition and satiety responsiveness $(P=0.53)$.

Food responsiveness and greatest observed engagement. There was a significant interaction between food responsiveness and condition $\left(F_{2,86}=4.50 ; P=0.014\right)$. Post-hoc simple main effects analyses for high and low food responsiveness adjusted for child age revealed that children with low food responsiveness in the PNM condition showed significantly lower engagement with the NF than children with low food responsiveness in the $\mathrm{MC}$ condition $(P=0 \cdot 012)$. There was no significant difference between the PNM and PM or the PM and

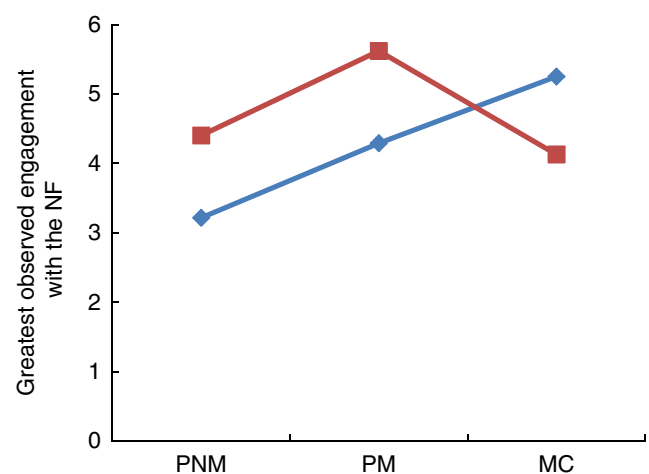

Fig. 1. Estimated marginal means of the engagement with the novel fruit (NF) by children, by condition and food responsiveness. Child age as covariate. PNM, prompting no modelling; PM, prompting and modelling; MC, modelling 'control' group. $\longrightarrow$, Low food responsiveness; - - , high food responsiveness. 
MC conditions in children with low food responsiveness. In contrast, in children with high food responsiveness, there was greater engagement with the NF in the PM condition than in the MC condition $(P=0.044)$. There was no significant difference between the PNM and PM or the PNM and MC conditions in children with high food responsiveness (Fig. 1).

\section{Enjoyment of food and greatest observed engagement.} There was a significant main effect of enjoyment of food on engagement $\left(F_{1,86}=5.21 ; P=0.025\right)$, with pairwise comparisons, demonstrating that those children who were reported to enjoy food more had the greatest observed engagement with the NF $(P=0.025$; low enjoyment mean engagement 4.3 (sD 1.8); high enjoyment mean engagement 4.9 (SD 1.5)). There was no significant interaction between condition and enjoyment of food $(P=0 \cdot 66)$.

\section{Discussion}

This study examined the relative efficacy of physical prompting techniques with and without parental modelling in the facilitation of acceptance of a NF by their children in comparison with parental modelling alone. We also examined how child foodapproach/avoidance characteristics would interact with these feeding practices to determine acceptance. We did not find evidence to support the hypothesis that children of caregivers who received instructions on how to physically prompt would be more likely to accept a novel fruit than children of caregivers who received no instructions on prompting. Indeed, overall, children who were in the physical prompting but not modelling group showed higher rates of NF refusal than children whose parents were not instructed to use physical prompting. This may suggest that physical prompting in the absence of modelling has similar effects to the use of verbal pressure to eat ${ }^{(8,19-21,35)}$. Importantly, this study also showed that there was no effect of physical prompting on rates of verbal pressure to eat used by parents, and therefore we can be confident that the differences seen between conditions are effects of physical prompting and not a general increase in pressure to eat.

We found some support for our hypothesis that children of caregivers who received instructions on how to prompt would be more likely to engage with a novel fruit if their caregivers also consumed the novel fruit compared with those whose caregivers had been instructed not to eat the NF. Children with high food responsiveness were more accepting of the NF in the prompting and modelling conditions than in the modelling control condition. However, this effect did not hold true for children with low food responsiveness, who showed greater acceptance of the NF in the condition where parents modelled intake but were not instructed to prompt and least acceptance in the prompting but no modelling condition. Owing to its potentially detrimental effect on acceptance, particularly in children with low food responsiveness, it is not feasible to recommend physical prompts as a method of increasing the likelihood of success of introduction of novel fruits to children. This study's results are further evidence that parental modelling is a crucial determinant of the successful introduction of a NF, and are consistent with previous studies that have shown the effectiveness of adult modelling for encouraging new food intake ${ }^{(12-13)}$. Modelling without tangible overt physical pressure appears to be the most effective strategy for facilitating NF acceptance in children with low food responsiveness.

We also found some support for our hypotheses that children showing higher food-approach (enjoyment of food) and lower food-avoidance (food fussiness) behaviours would be more accepting of the NF. This is consistent with previous studies that have shown that these traits are predictive of children's food intake and weight trajectories ${ }^{(28,29)}$. The fact that the effectiveness of parental prompting depended upon children's food responsiveness but did not interact with children's enjoyment of food, food fussiness or satiety responsiveness requires further investigation. Previous studies have demonstrated that children's food responsiveness is significantly related to faster eating and greater total energy intake ${ }^{(29)}$, more rapid growth and greater weight gain ${ }^{(36)}$, suggesting that it is a good indicator of a child's food-approach tendencies and appetite. Food responsiveness has also been associated with greater parental use of restrictive feeding practices, whereas enjoyment of food has been associated with lower parental pressure to eat, and both satiety responsiveness and fussiness are associated with greater pressure to eat, irrespective of child weight ${ }^{(28)}$. Therefore, further studies could examine how a child's experience of typically restrictive feeding practices might interact with parental prompting to eat in determining the acceptance of new foods. The interaction of parental feeding practices with children's individual differences has received scant attention in the literature, although a small number of studies have called for attention to be paid to this when evaluating the effectiveness of interventions focusing on parental feeding practices - for example, Gubbels et $a l .{ }^{(37)}$ demonstrated that parenting practices had a much stronger relationship with children's diet quality when the child had a favourable behavioural style, favourable eating style or lower BMI. Together with the present study, this emphasises the need to examine children's individual differences when evaluating potential intervention strategies. This study suggests that food responsiveness may be a particularly important characteristic to examine in such contexts.

Blissett et $a l .{ }^{(18)}$ showed that the number of parental physical prompts used during a mealtime that included a NF was associated with NF acceptance. Owing to the naturalistic observational methodology used in this previous study, it was unclear whether parental physical prompting facilitated intake or whether parents of children who were more willing to taste such foods used the practice more readily. In light of the findings of the current study, it appears that children who are willing to taste new foods elicit or reinforce the use of parental physical prompting. Although we did not find evidence in the current study that physical prompts are a useful mechanism for those children who with low food responsiveness, it may be that prompting facilitates acceptance in those children with higher food acceptance. This is consistent with other studies examining children's compliance with maternal verbal prompts to eat - for example, girls who show greater compliance with maternal prompts to eat are more likely to become overweight 
or obese and gain relatively more weight across time than their less compliant peers ${ }^{(38)}$. Furthermore, children of obese mothers are more compliant with prompts to eat than the children of non-obese mothers ${ }^{(39)}$.

There are a number of limitations to this study. The participants who sign up to the Infant and Child Laboratory database tend to be well educated, relatively affluent, and therefore not particularly representative of families where fruit and vegetable consumption is very poor. Therefore, these findings may not replicate in lower socio-economic status contexts. Although we gave much information to parents about how we wanted them to behave during the feeding session, we needed to exclude several parents from the analysis due to non-compliance. We used a per-protocol analysis rather than an intention-to-treat analysis, which yielded a smaller sample size and resultant loss of power. Another concern is that parents completed the questionnaire measures after they had eaten the meal with their child, and thus their ratings of general traits of their child's food approach and avoidance may have been more reflective of the child's eating behaviour in that session than would be typically reported. Furthermore, some parents in the modelling 'control group' condition spontaneously used physical prompts to eat. We did not exclude these individuals from the analysis, but when making comparisons between the prompting groups and the control group we were mindful that a small amount of physical prompting also took place in this group. A fourth condition, with caregivers who used no prompting or modelling, would have provided a potentially useful comparison, although one that lacked ecological validity. As the NF we used differed between groups, to ensure the novelty of the fruit to all participants, it was not possible to compare the grams consumed by the children in each condition. Therefore, we had to calculate the percentage of the fruit that was consumed. Although there were no significant differences in children's eating behaviours based on the fruits used, it is possible that variability in the taste, texture or amount of the NF presented may have had a small effect on the amount of the food consumed. This potentially explains why the effects that were significant were predominantly for the degree of engagement with the NF rather than the measure of consumption. Furthermore, the longer-term effects of physical prompting on food acceptance in children with high food responsiveness are unknown.

In conclusion, although some parents can be taught to use physical prompting strategies that, in combination with modelling of NF intake, may facilitate acceptance of NF in food-responsive children, physical prompting in the absence of modelling is likely to be detrimental to NF acceptance for many children. In children with low food responsiveness, modelling consumption best promotes acceptance. These findings emphasise the need to examine children's individual differences in food approach and avoidance when recommending intervention strategies designed to improve the range of foods accepted by children with poorer diets.

\section{Acknowledgements}

Thanks to Muazzez Dogukan for assistance with video coding and inter-rater reliability.
Funded by the Feeding For Life Foundation (grant reference number 11-1170).

J. B., G. H. and S. H. formulated the research questions and designed the study; C. B. and A. F. collected all data, coded observations, entered data and carried out elements of data analysis; J. B. took primary responsibility for supervision of the study and carried out the majority of data analysis. All the authors contributed to the writing of the manuscript and have approved the final version.

The authors have no conflicts of interest to declare.

\section{References}

1. World Health Organization (2003) Diet, Nutrition and the Prevention of Chronic Diseases Technical Report Series, no. 916. Geneva: WHO.

2. Hossain P, Kawar B \& El Nahas M (2007) Obesity and diabetes in the developing world - a growing challenge. $N$ Engl J Med 356, 213-215.

3. Cashdan E (1994) A sensitive period for learning about food. Hum Nat 5, 279-291.

4. Harris G (1993) Introducing the infant's first solid food. Br Food J 95, 7-10.

5. Skinner JD, Carruth BR, Bounds W, et al. (2002) Children's food preferences: a longitudinal analysis. J Am Diet Assoc 102, 1638-1647.

6. Aresu M, Chaudhury M, Diment E, et al. (2010) Health Survey for England 2009. London: NHS, The Information Centre.

7. Blissett J \& Fogel A (2013) Intrinsic and extrinsic influences on children's acceptance of new foods. Physiol Behav 121, 89-95.

8. Wardle J, Carnell S \& Cooke L (2005) Parental control over feeding and children's fruit and vegetable intake: how are they related? J Am Diet Assoc 105, 227-32.

9. Maier AS, Chabanet C, Schaal B, et al. (2008) Breastfeeding and experience with variety early in weaning increase infants' acceptance of new foods for up to two months. Clin Nutr 27, 849-857.

10. Mitchell GL, Farrow C, Haycraft E, et al. (2013) Parental influences on children's eating behaviour and characteristics of successful parent-focussed interventions. Appetite 60, 85-94.

11. Fisher JO, Mitchell DC, Smiciklas-Wright H, et al. (2002) Parental influences on young girls' fruit and vegetable, micronutrient and fat intakes. J Am Diet Assoc 102, 58-64.

12. Harper LV \& Sanders KM (1975) The effect of adults' eating and young children's acceptance of unfamiliar foods. $J$ Exp Child Psychol 20, 206-214.

13. Hendy HM \& Raudenbusch B (2000) Effectiveness of teacher modeling to encourage food acceptance in preschool children. Appetite 34, 61-76.

14. Wind M, De Bourdeaudhuij I, te Velde SJ, et al. (2006) Correlates of fruit and vegetable consumption among 11-year-old Belgian-Flemish and Dutch schoolchildren. J Nutr Educ Behav 38, 211-221.

15. Baranowski T, Cullen KW \& Baranowski J (1999) Psychosocial correlates of dietary intake: advancing dietary intervention. Annu Rev Nutr 19, 17-40.

16. Hearn MD, Baranowski T, Baranowski J, et al. (1998) Environmental influences on dietary behaviour among children: availability and accessibility of fruits and vegetables enable consumption. J Health Educ 29, 26-32.

17. Clark HR., Goyder E, Bissell P, et al. (2007) How do parents' child-feeding behaviours influence child weight? Implications for childhood obesity policy. J Public Health 29, 132-141. 
18. Blissett J, Bennett C, Donohoe J, et al. (2012) Predicting successful introduction of novel fruit to preschool children. J Acad Nutr Diet 112, 1959-1967.

19. Moore SN, Tapper K \& Murphy S (2007) Feeding strategies used by mothers of 3-5-year-old children. Appetite 49, 704-707.

20. Brown KA, Ogden J, Vögele J, et al. (2008) The role of parental control practices in explaining children's diet and BMI. Appetite 50, 252-259.

21. Galloway AT, Fiorito LM, Francis LA, et al. (2006) 'Finish your soup': counterproductive effects of pressuring children to eat on intake and affect. Appetite 46, 318-323.

22. Blissett J (2011) Relationships between parenting style, feeding style and feeding practices and fruit and vegetable consumption in early childhood. Appetite 57, 826-831.

23. Cooke L, Wardle J \& Gibson EL (2003) Relationship between parental report of food neophobia and everyday food consumption in 2-6-year-old children. Appetite 43, 205-206.

24. Coulthard H \& Blissett J (2009) Fruit and vegetable consumption in children and their mothers. Moderating effects of child sensory sensitivity. Appetite 52, 410-415.

25. Dovey TM, Staples PA, Gibson EL, et al. (2008) Food neophobia and 'picky/fussy' eating in children: a review. Appetite 50, 181-193.

26. Pliner P \& Hobden K (1992) Development of a scale to measure the trait of food neophobia in humans. Appetite 19, 105-120.

27. Ashcroft J, Semmler C, Carnell S, et al. (2007) Continuity and stability of eating behaviour traits in children. Eur J Clin Nutr 62, 985-990.

28. Webber L, Hill C, Saxton J, et al. (2008) Eating behaviour and weight in children. Int J Obes 33, 21-28.

29. Carnell S \& Wardle J (2007) Measuring behavioural susceptibility to obesity: validation of the child eating behaviour questionnaire. Appetite 48, 104-113.
30. Wardle J, Guthrie CA, Sanderson S, et al. (2001) Development of the children's eating behaviour questionnaire. I Child Psychol Psychiatry 42, 963-970.

31. Tharner A, Jansen PW, Kiefte-de Jong JC, et al. (2014) Toward an operative diagnosis of fussy/picky eating: a latent profile approach in a population-based cohort. Int J Behav Nutr Phys Act 11, 14.

32. Pliner P (1994) Development of measures of food neophobia in children. Appetite 23, 147-163.

33. Haycraft EL \& Blissett JM (2008) Maternal and paternal controlling feeding practices: reliability and relationships with BMI. Obesity 16, 1552-1558.

34. Martin N, Oliver C \& Hall S (1999) ObsWin: observational data collection \& analysis for Windows. CTI Psychol Software News 9, 14-16.

35. Patrick H, Nicklas TA, Hughes SA, et al. (2005) The benefits of authoritative feeding style: caregiver feeding styles and children's food consumption patterns. Appetite $\mathbf{4 4}$, 243-249.

36. van Jaarsveld CH, Boniface D, Llewellyn CH, et al. (2014) Appetite and growth: a longitudinal sibling analysis. JAMA Pediatr 168, 345-350.

37. Gubbels JS, Kremers SP, Stafleu A, et al. (2009) Diet-related restrictive parenting practices. Impact on dietary intake of 2-year-old children and interactions with child characteristics. Appetite 52, 423-429.

38. Faith MS, Heo M, Kral TV, et al. (2013) Compliant eating of maternally prompted food predicts increased body mass index $z$-score gain in girls: results from a populationbased sample. Child Obes $\mathbf{9}, 427-436$.

39. Lumeng J. C. \& Burke L. M (2006) Maternal prompts to eat, child compliance, and mother and child weight status. J Pediatr 149, 330-335. 